\title{
The Inclusive Review on SARS-CoV-2 Biology, Epidemiology, Diagnosis, and Potential Management Options
}

\author{
Arezoo Beig Parikhani ${ }^{1} \cdot$ Masoume Bazaz $^{1} \cdot$ Hadi Bamehr $^{1}$. Sepideh Fereshteh ${ }^{2}$. Shahin Amiri ${ }^{1}$. \\ Mostafa Salehi-Vaziri ${ }^{3,5} \cdot$ Arash Arashkia $^{4,5}$ (I) Kayhan Azadmanesh ${ }^{4,5}$
}

Received: 14 September 2020 / Accepted: 7 February 2021 / Published online: 27 February 2021

(c) The Author(s), under exclusive licence to Springer Science+Business Media, LLC part of Springer Nature 2021

\begin{abstract}
A novel coronavirus member was reported in Wuhan City, Hubei Province, China, at the end of the year 2019. Initially, the infection spread locally, affecting the Wuhan people, and then expanded rapidly throughout the world. On 11 March 2020, the World Health Organization (WHO) proclaimed it a global pandemic. The virus is a new strain most closely related to a bat coronavirus (RaTG13) which was not previously discovered in humans and is now formally known as the severe acute respiratory syndrome coronavirus 2 (SARS-CoV-2). Coronavirus disease 2019 (COVID-19) is the disease syndrome that the SARS-CoV-2 virus triggers. It is suggested that SARS-CoV-2 can be transmitted through aerosols, direct/indirect contact, and also during medical procedures and specimen handling. The infection is characterized by isolated flu-like symptoms, but there may be specific signs of fever, fatigue, cough, and shortness of breath, as well as the loss of smell and breathing difficulty. Within this report, we tried to review the most current scientific literature published by January 2021 on various aspects of the outbreak, including virus structure, pathogenesis, clinical presentation, epidemiology, diagnostic approaches, potential therapeutics and vaccines, and prospects. We hope this article makes a beneficial impact on public education to better deal with the SARS-CoV-2 crisis and push a step forward in the near term towards its prevention and control.
\end{abstract}

\section{Introduction}

In early December 2019, an outbreak of pneumonia of unknown etiology occurred in Wuhan City, Hubei Province, China. On 31 December 2019, researchers at the Wuhan Institute of Virology conducted a metagenomic

Arezoo Beig Parikhani and Masoume Bazaz have equally contributed to the preparation of the manuscript and might be considered as the co-first authors.

Arash Arashkia

a_arashkia@pasteur.ac.ir

1 Department of Medical Biotechnology, Biotechnology Research Center, Pasteur Institute of Iran, Tehran, Iran

2 Department of Bacteriology, Pasteur Institute of Iran, Tehran, Iran

3 Department of Arboviruses and Viral Hemorrhagic Fevers, Pasteur Institute of Iran, Tehran, Iran

4 Department of Molecular Virology, Pasteur Institute of Iran, Tehran, Iran

5 Research Centre for Emerging and Reemerging Infectious Diseases, Pasteur Institute of Iran, Tehran, Iran analysis on the bronchoalveolar lavage samples using the next-generation sequencing (NGS) process, which led to the identification of the causative agent of disease that was dubbed as nCoV-2019 by WHO [1]. Eventually, the Coronaviridae Study Group (CSG) formally named the virus as SARS-CoV-2 based on phylogeny, taxonomy, and proven experience [2]. The rapid human-to-human transmission rate of the virus contributed to the dissemination of the disease to other countries around the world and was formally declared as a pandemic by the WHO on 12 March 2020 [3].

First human coronaviruses OC43 and 229E were identified in the 1960s, followed by the identification of SARSCoV in 2003, HCoV-NL63 in 2004, HKU1 in 2005, MERS$\mathrm{CoV}$ in 2012, and finally SARS-CoV-2 in 2019 [3]. These enveloped virions have the longest positive-sense RNA genome among RNA viruses, which carry diseases in mammals and birds [4]. In humans, coronaviruses can cause minor respiratory infections, like the common cold. Nonetheless, the rarer zoonotic forms, such as SARS, MERS, and SARS-CoV-2, may be lethal [5]. SARS-CoV-2 can invade the lower respiratory tract and cause pneumonia in human beings, while the symptoms are milder, relative to SARS and MERS [5]. This virus can attach to its receptor, the 
human receptor angiotensin-converting enzyme 2 (ACE2), and mediate membrane fusion and viral entry by the spike protein, which is the key target for antibody-mediated neutralization [6]. The disease is mainly transmitted during close contact through respiratory droplets (such as coughing and sneezing) [7]. Therefore, it is recommended to maintain a safe distance, wear masks and gloves, and wash hands regularly to avoid disease transmission. The SARS-CoV-2 pandemic has pressured the world to work and better understand the essence of the virus, seeking solutions and concerns regarding this epidemic to find a cure and vaccine for the disease when coping with the outbreak and managing patients. Given the significance of the SARS-CoV-2 and its increasing prevalence, the current review aims to present the latest knowledge about the structure, proliferation, epidemiology, and pathogenesis and points out the clinical diagnostic approaches and therapeutic steps taken for the disease centered on the latest papers published in this field.

\section{COVID-19 and Its Origin}

In December 2019, pneumonia of unknown cause was diagnosed in patients in Wuhan, China. Earlier studies reported that a large number of primary pneumonia cases were associated with the products sold in the Seafood Wholesale Market in Wuhan, which was disinfected on 30 December 2019, and officially closed on 1 January 2020 [8]. This market was a large place in an area of $50,000 \mathrm{~m}^{2}$, where seafood, fresh meat, perishable goods, and a wide variety of wildlife were sold for consumption.

The WHO in Beijing issued a study from a group of pneumonia patients of an unexplained origin in the same town by 31 December. A few days later, investigators at Wuhan Institute of Virology introduced a new coronavirus as the possible cause of the disease by conducting a metagenomic analysis using NGS techniques on bronchoalveolar lavage samples. Similar to SARS-CoV, the new virus attaches to ACE2 receptor [1]. However, due to the low expression of ACE2 in the respiratory system, it is now hypothesized that co-receptors, alternative receptors, and attachment, factors, including heparan sulfate, neuropilins, sialic acids, GRP78, and CD147 (BSG), may contribute to the virus entry and tropism [9].

The current state of a public health emergency is somewhat comparable to the outbreak of SARS in southern China in 2002. The prevalence of both viruses started in winter in cases exposed to live animals sold in animal markets, and both of them were caused by unknown causes [10]. Emerging viruses transmitted from animal hosts to humans are among the world's most recognized fatal diseases. SARS-CoV and MERS-CoV are both such zoonoses, and the incidence of two mutations in the $\mathrm{S}$ and $\mathrm{N}$ proteins of
SARS-CoV-2 may suggest its transmission from an animal [11]. SARS-CoV-2 is thought to be transmitted from animals, although it is not yet clear which animal the virus has originated from. According to the latest results, the SARSCoV-2 shares $79.5 \%$ of the genetic sequence with SARS$\mathrm{CoV}$ and possesses $96.2 \%$ homology to a bat coronavirus (HKU9-1) [1].

The risk and dynamics of cross-species or human-tohuman transmission of coronavirus are influenced by various factors, such as the host immune system, host receptors, proliferation rate, and rate of virus mutation [12].

This is the third serious coronavirus incursion into humans in less than 20 years, and SARS-CoV-2 has now greatly surpassed SARS and MERS in the number of infected patients. The COVID-19 mortality rate is reported to be approximately $2 \%$, which is lower than SARS (9.5\%) and MERS (30\%) [10], although a true denominator of numbers infected has not been determined.

\section{The Genealogy and Structure of the Coronaviruses}

Human coronaviruses are members of the Nidovirales order, which comprises the Coronaviridae, Arteriviridae, and Roniviridae families. Coronavirinae and Torovirinae are two subfamilies of the Coronaviridae. The Coronavirinae subfamily is further classified into four Alpha, Beta, Gamma, and Delta groups, the first two of which infect mammals, and the second two infect birds. Primarily, the viruses were categorized into these groups based on serology, but currently, they are classified based on phylogenetic classification. All coronaviruses belong to the Baltimore class IV viruses (positive-sense single-strand RNA) and are enveloped. To date, seven species of human coronaviruses have been described: HCoV-NL63 and HCoV-229E, which belong to the Alpha genus, and HCoV-OC43, HCoVHKU1, SARS-CoV, MERS-CoV, and SARS-CoV-2 belonging to the Beta genus. $\beta$-Coronaviruses are enveloped, singlestranded RNA viruses that infect wild animals, herds, as well as human beings, triggering unanticipated outbreaks and asymptomatic infections. While bats are a prime suspect as the source of the virus, there may be an intermediary host in the bat-human transmission chain (Fig. 1) [12].

Phylogenetic tree analysis based on the complete genome showed that the SARS-CoV-2 virus was closely related to the SARS bat virus, SCCoVZC21 strain (NCBI accession number MG772934), and bat-SL-CoVZC45 (NCBI accession MG772933) with approximately $89 \%$ sequence homology. Its genomic structure is similar to that of common $\beta$-coronaviruses. Further phylogenetic analysis has shown that SARS-CoV-2 is a recombinant virus that is closely associated with those of bats. Recent studies have demonstrated, 


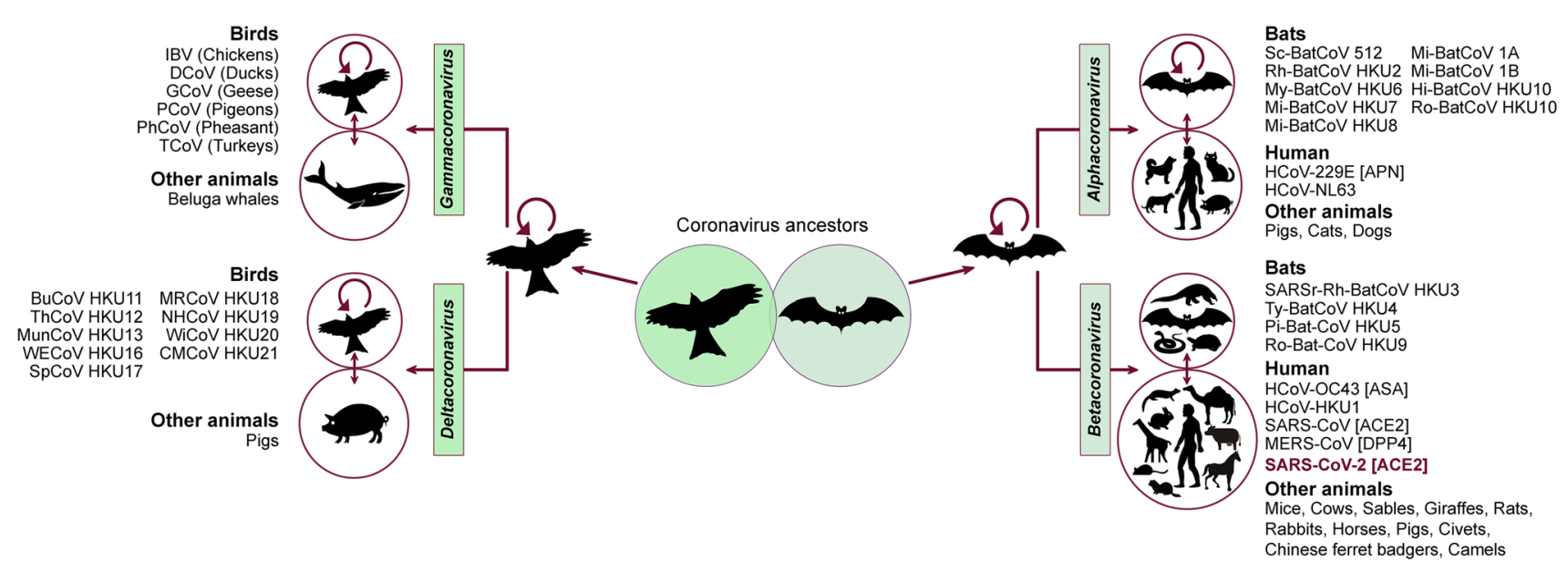

Fig. 1 The key reservoirs and cross-species transmission of coronaviruses. Coronaviruses have evolved from their ancestors in bat and bird hosts to new virus species that infect other animals

however, that RaTG13, bats coronavirus, has the most similarity with the novel coronavirus (92-96\% similarity) and establishes a separate order from other coronaviruses. As such, the analysis of the novel coronavirus rejects the hypothesis of emergence as a result of a recent recombination event [13].

In the last 18 years, two zoonotic and highly pathogenic species of coronavirus family have been identified, known as SARS-CoV and MERS-CoV [14]. Coronaviruses are spherical, polyhedral viruses, ranging from 80 to $160 \mathrm{~nm}$ in diameter, and constitute a large genome size ( 27.6-31.6 kb) [15] Club-like surface projections or peplomers [composed of trimers of a spike (S) protein] are evident in electron microscopic images of the coronavirus [16]. The virus envelope is protected by a membrane glycoprotein $(\mathrm{M})$, which is the most abundant structural protein of the virus [16]. The M protein forms the virus and strengthens the curvature of the membrane and attaches to the nucleocapsid. Moreover, the envelope contains a small amount of a transient membrane protein known as coat protein $(\mathrm{E})$, which plays a role in the assembly, release, and pathogenesis of the virus [5]. The nucleocapsid $(\mathrm{N})$ is another viral protein that binds to the RNA genome, creating a symmetrical helical nucleocapsid (Fig. 2). Also, nucleocapsids have two domains, which can adhere to the RNA genome through various mechanisms $[5,16]$.

Coronaviruses have a single-stranded, positive-sense RNA genome that has a cap at $5^{\prime}$ terminus, poly (A) tail at $3^{\prime}$ terminus, and several open reading frames (ORFs). The consistent arrangement of genes from $5^{\prime}$ to $3^{\prime}$ end includes replicase, S-E-M-N glycoproteins, along with several small ORFs representing sub-proteins that are scattered among structural genes (Fig. 3). Coronavirus replicase is encoded by two sizable overlapping ORFs (ORF1a and ORF1b), dominating two-thirds of the genome [17]. The

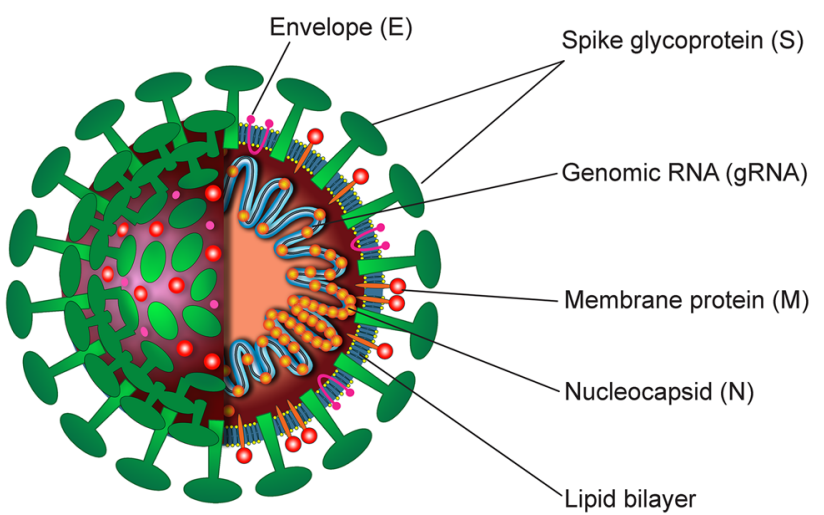

Fig. 2 The schematic structure of SARS-CoV-2 and its structural proteins. The spike, envelope, and membrane glycoproteins are embedded in the lipid bilayer, and nucleocapsid protein binds to genomic RNA

rapid sequencing of the nearly 30,000 nucleotides of the SARS-CoV-2 genome was accomplished in approximately 3 weeks from the time of the first hospitalized patient who was diagnosed on 12 December 2019, by Zhang's group and several others in China. The SARS-CoV-2 genome contains 14 ORFs encoding 27 proteins. The orfla and orf $1 \mathrm{~b}$ genes are located at the $5^{\prime}$ terminus of the genome and encode 15 non-structural proteins (NSPs) from nsp1 to nsp10 and from nsp12 to nsp16, respectively. On the other hand, the $3^{\prime}$ terminus of the genome contains four structural proteins $(\mathrm{S}, \mathrm{E}, \mathrm{M}$, and $\mathrm{N}$ ) and eight secondary proteins (3a, 3b, p6, $7 \mathrm{a}, 7 \mathrm{~b}, 8 \mathrm{~b}, 9 \mathrm{~b}$, and orf14). Even though at the level of amino acid SARSCoV-2 is mostly similar to the SARS-CoV, there are considerable differences between the two viruses, such as a significant difference in spike RBD in the two regions interacting with ACE2 which makes previously produced antibodies and therapeutic peptides for the SARS-CoV spike 


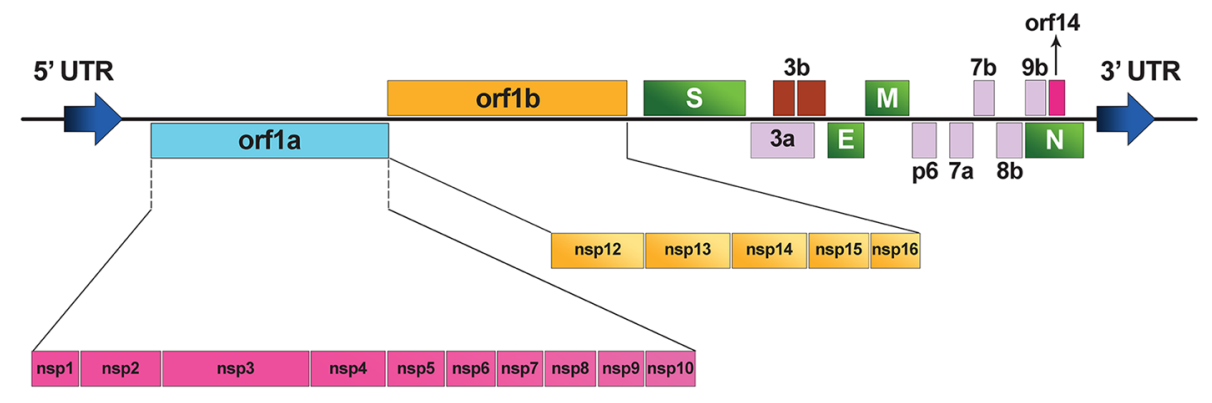

Fig. 3 Genome structure of SARS-CoV-2 and its encoded proteins. The open reading frame $1 \mathrm{a}(\mathrm{ORF} 1 \mathrm{a})$ and ORF1b are shown as blue and orange boxes, respectively, that encode 15 non-structural proteins (NSPs). The genes encoding main structural proteins, including spike

RBD not to function properly against SARS-CoV-2 [17]. In addition, lack of $8 \mathrm{a}$ protein and having larger $8 \mathrm{~b}$ protein in SARS-CoV-2 relative to SARS-CoV have been shown as noticeable differences in a systematic comparison [17]. SARS-CoV-2 has also been demonstrated to be more capable of infecting and replicating in human lung tissues than SARS-CoV [18]. Therefore, further studies are needed to describe how these differences affect the infection, replication, and pathogenesis of SARS-CoV-2.

\section{Proliferation and Survival in Host Cells}

Similar to other viruses, coronaviruses rely on the cells of other organisms to survive and reproduce. The replication and proliferation stages of coronavirus include binding and entry into the host cell, translation of viral replicase, genome transcription, replication, translation of structural proteins, and arranging and releasing the virus (Fig. 4).

\section{Binding and Entry into the Host Cell}

Binding starts with the attachment of the virus to the cell surface through the connection of the spike protein to a cell-surface receptor. The spike protein consists of two subunits, $\mathrm{S} 1$ and $\mathrm{S} 2$, with $\mathrm{S} 1$ at the $\mathrm{N}$-terminus providing the receptor-binding function and $\mathrm{S} 2$ at the $\mathrm{C}$-terminus providing fusion activity. The cleavage site of $\mathrm{S} 1 / \mathrm{S} 2$ in coronavirus is mediated by one or several host proteases. Similar to SARS-CoV, the spike protein is cleaved by TMPRSS2 in SARS-CoV-2 [19]. The binding between the $\mathrm{S} 1$ subunit and the receptor initiates severe conformational changes in $\mathrm{S} 2$ subunits, which leads to the fusion between the virus and cellular membrane, and the release of nucleocapsid in the cytoplasm [16]. SARS-CoV and SARS-CoV-2 bind to ACE2 receptor, which is widely
$(\mathrm{S})$, envelope $(\mathrm{E})$, membrane $(\mathrm{M})$, and nucleocapsid $(\mathrm{N})$, are represented as green boxes. The purple, red, and pink boxes on the $3^{\prime}$ end represent the secondary (accessory) proteins (Color figure online)

expressed with the preserved original structure across a variety of animals, including fish, amphibians, reptiles, birds, and mammals [20]. It seems that SARS-COV-2 can also bind to BSG (CD147) receptor [9]. The receptorbinding domain (RBD) of spike glycoprotein is responsible for the entry of coronaviruses into the host cells. Although the RBDs from SARS-COV and SARS-COV-2 share $72 \%$ identity in amino acid sequences, molecular modeling revealed that SARS-CoV-2 RBD has a stronger interaction with ACE2 [21]. Furthermore, Ming and Zheng in China reported that while the spike protein of SARSCoV-2 was found to be approximately $75 \%$ homologous to the SARS-CoV spike, they also had significant antigenic differences [22].

Following the viral entry into the host cell and elimination of the envelope, the RNA genome of the virus acts as a transcript and leads to the translation of ORF1a and ORF1b from the 5 '-end of the capped viral genome, followed by the translation of PP1a and PP1b. After translation, the mentioned proteins undergo spontaneous cleavage, causing the formation of 15-16 non-structural proteins with various functions.

\section{Viral Transcription and Translation}

By modeling the genomic RNA, the coronavirus replicase gene produces a full-length negative-sense antigenome that acts as a template for the production of a new RNA genome [16]. Also, the polymerase can alter the string pattern during discontinuous genome transcription and create a complex set of negative subgenomic RNA (sgRNA) strands used as a template for creating a complex set of positive sgRNA strands [16]. While $\mathrm{S}, \mathrm{M}$, and E proteins are translated and released in the endoplasmic reticulum, $\mathrm{N}$ protein is released in the cytoplasm after translation. Most structural proteins of the virus undergo post-translational changes that are essential for their function [17]. 


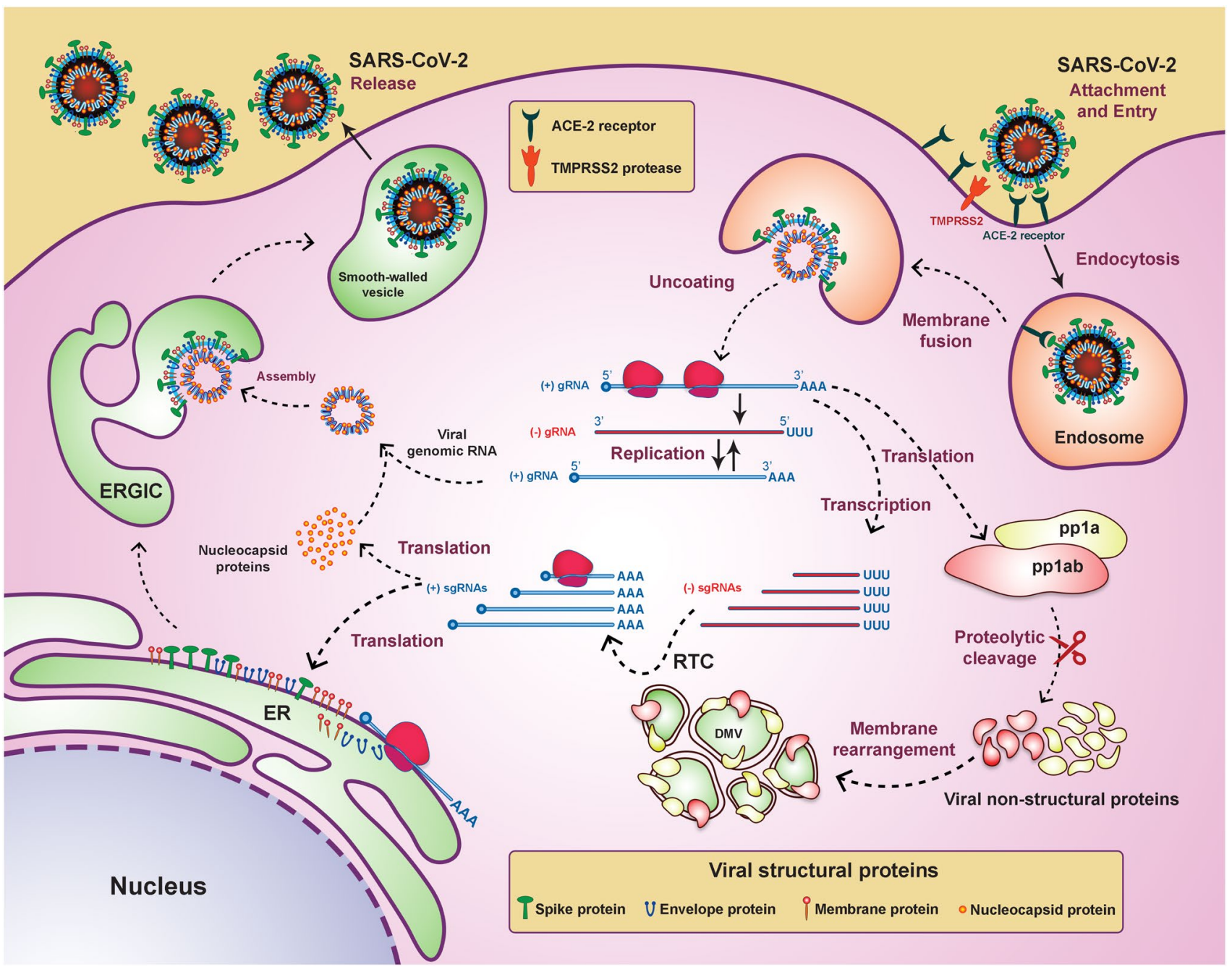

Fig. 4 The SARS-CoV-2 life cycle in the host cell. After attachment to its receptor, the virus enters the cytosol through the endosomal pathway. The next step in the coronavirus lifecycle entails the translation of the virion's replicase gene from genomic RNA (gRNA), which forms two co-terminal polyproteins, pp1a and pplab. These proteins produce various non-structural proteins (nsps) following the proteolysis processes. Approximately all nsps merge into the ReplicaseTranscriptase Complex (RTC) to render a region suitable for RNA synthesis and are unanimously responsible for replication and transcription of subgenomic RNA (sgRNA). The sgRNAs act as mRNAs for the structural as well as accessory genes that are located down-

\section{Virion Assembly and Release}

Viral assembly occurs in the ER-Golgi Intermediate Compartment (ERGIC) in coordination with M protein [16]. The interaction between $\mathrm{M}$ proteins generates the scaffold of the virion envelope, and $\mathrm{M}-\mathrm{S}$ and $\mathrm{M}-\mathrm{N}$ interactions facilitate the transport of other viral proteins to the assembly site stream of polyprotein replicase. Both gRNAs and sgRNAs are produced via ribosomal frameshifting that generates intermediate RNAs by discontinues transcription. Upon replication and synthesis of the (+) sgRNA, the viral structural proteins, including S, E, and M, are translated into the endoplasmic reticulum (ER), and pass through the secretory cycle into the endoplasmic Reticulum-Golgi intermediate compartment (ERGIC). Subsequently, the virus genome, covered by $\mathrm{N}$ protein, buds inside the ERGIS membrane, which is composed of other viral structural proteins. After assembly, the particles are transported to the cell exterior via vesicles and released by exocytosis

[23]. Also, the CoV E protein has a well-established role in the assembly of components through interaction with the $\mathrm{M}$ protein and induces membrane curving [23]. Ultimately, coronavirus particles assembled in the ER-Golgi intermediate compartment (or ERGIC) bind to vesicles and are transported by the exocytosis through the secretory pathway [17]. 


\section{Pathogenesis of COVID-19 and Its Interaction with the Immune System}

Before 2019, there were only six CoVs which were known to infect humans and cause respiratory diseases. SARS$\mathrm{CoV}$ and MERS-CoV, while detectable in the upper respiratory tract, can infect the lower respiratory tract, causing severe respiratory syndrome. Likewise, SARS$\mathrm{CoV}-2$ infects the lower respiratory tract and causes severe pneumonia, mainly due to inflammasome activation and pyroptosis [24]. Both classical and non-classical pyroptosis signaling pathways can cause IL- $1 \beta$ release. Studies show that IL- $1 \beta$ increases in the serum of patients with SARS-CoV-2, and it seems that the virus causes cellular pyroptosis in the lymphocytes through the activation of NLRP3 [25].

The infection begins via the entry of the SARS-CoV-2 into the epithelial cells. Subsequently, the virus induces apoptosis and the host cells get damaged and lysed following the virus replication, and the viral antigens are presented to $\mathrm{CD}^{+} \mathrm{T}$ cells as well as natural killer (NK) cells. The subepithelial dendritic cells (DC), as well as tissue macrophages $(\mathrm{M} \Phi)$, can recognize SARS-CoV-2 antigens and present them to $\mathrm{CD} 4^{+} \mathrm{T}$ cell through $\mathrm{MHC}$ class II molecules following the epithelium disruption, and trigger the differentiation of the $\mathrm{T}$ cells into memory Th1, Th17, and $\mathrm{T}$ follicular helper $\left(\mathrm{T}_{\mathrm{FH}}\right)$ cells. The $\mathrm{T}_{\mathrm{FH}}$ cells can help B lymphocytes differentiate into plasma cells (PC) and promote the generation of several isotypes of antibodies which start with IgM production [26]. On the other hand, B cells are capable of directly recognizing SARS-CoV-2 and presenting the viral antigens to Th lymphocytes by MHC class II molecules which then contribute to the induction of $\mathrm{M} \Phi$. Following the primary $\operatorname{IgM}$ response, isotype switching towards IgG occurs that potentially could lead to long-term immunity [27]. But this concept has remained a major challenge since SARSCoV-2 seems to be able to impair the development of longlived antibody responses by blunting the germinal center (GC) response [28]. B cell lymphopenia has also been reported in severe SARS-CoV-2 infection [29]. Moreover, the generation of long-term memory $\mathrm{T}$ cell responses is still unclear [28]. In patients with COVID-19, functional impairment and overexpression of either activation or exhaustion markers, such as FAS, TRAIL, and caspase 3, have been reported in the case of $\mathrm{CD}^{+}$and $\mathrm{CD} 8^{+} \mathrm{T}$ cells. This evidence can be considered as the key cause for $\mathrm{T}$ cell depletion or lymphopenia in severe cases [30].

After identifying the RNA of the virus, the signaling cascades pathway of NF-kB and IRF3 is activated. These transcription factors in the nucleus initiate gene expression for inflammatory cytokines and IFN-I, which results in the immune system's initial response to a viral attack [31]. While the viral infection is suppressed by the primary immune response, the SARS-CoV-2 utilizes mechanisms to escape the immune response, including cytosolic sensor/ RNA suppression and ubiquitination, thereby decomposing the sensor. Lack of suppressing the virus with a proper primary response leads to viral replication and propagation, which results in the production of large amounts of INF-I, followed by neutrophil and macrophages chemotaxis into the lungs, causing cytokine storm syndrome [31]. Cytokine release syndrome and lymphopenia have been reported as the main pathological findings in patients with coronavirus disease in the acute stage [32]. Furthermore, peripheral lymphocyte subset change has been reported to be associated with clinical characteristics and treatment efficacy of COVID-19 [33]. The number of inflammatory cytokines (e.g., MIP-1A, MCP-1, IP-10, G-CSF, IL-10, IL-7, IL-2, and TNF $\alpha$ ) increases in the lungs of patients, which play a major role in the pathogenesis of COVID-19 [31, 33].

While research has shown that macrophages and $\mathrm{T}$ cells express small amounts of the ACE2 receptor in the lungs, SARS-CoV-2 has been reported to directly infect the macrophages and T cells, assuming that COVID-19 may enter cells through another receptor or antibody and receptordependent pathways [31,33]. Also, the Thelper cell 1 (Th1) plays a vital role in viral infections and is recognized as the most important possible factor in SARS-CoV-2 control [34].

\section{Human-to-Human Transmission of SARS-CoV-2}

Transmission of the virus among humans can occur via multiple routes: (1) close person-to-person contact, (2) bioaerosol droplets, and (3) touching contaminated surfaces [35]. It is presumed that the virus is transmitted by respiratory droplets when symptomatic people sneeze or cough, expelling virus-containing droplets up to one meter in the air, which could land on mucous membranes of the mouth, nose, or eyes of nearby people. The droplets remain in the air for a short period. However, since the coronavirus can survive from several hours to several days, the virus may be transmitted indirectly via fomites, such as clothes, dining utensils, and home appliances. Since the coronavirus can infect the gastrointestinal tract, fecal-oral transmission might be possible. Another avenue is through "hidden transmission," in which asymptomatic infected individuals or carriers unknowingly transmit the virus to unsuspecting contacts [36].

Various types of biocidal agents, such as hydrogen peroxide, alcohols, sodium hypochlorite, or benzalkonium 
chloride, are used worldwide for disinfection, mainly in healthcare settings. Ethanol (78-95\%), 2-propanol (70-100\%), a combination of 2-propanol (45\%) with 1-propanol $(30 \%)$, glutaraldehyde $(0.5-2.5 \%)$, formaldehyde $(0.7-1 \%)$, and povidone-iodine $(0.23-7.5 \%)$ easily inactivate coronaviruses. The minimum concentration of sodium hypochlorite required for disinfection is $0.21 \%$. On the other hand, hydrogen peroxide is effective at a concentration of $0.5 \%$ and an incubation time of $1 \mathrm{~min}$. Meanwhile, benzalkonium chloride is effective with an incubation time of $10 \mathrm{~min}$ and a concentration of $0.05 \%$. Human coronaviruses can remain infectious on inanimate surfaces at room temperature for up to 9 days. At a temperature of $30{ }^{\circ} \mathrm{C}$ or more, the duration of persistence is shorter [37].

Although the viral load of coronaviruses on inanimate surfaces is not known during an outbreak situation, it seems plausible to reduce the viral load on surfaces by disinfection, especially for frequently touched surfaces in the immediate patient surrounding where the highest viral load can be expected [37].

Recently, several reports have been published about the possible role of environmental factors, especially air temperature and humidity, in the transmission of the SARSCoV-2. Considering contradictory reports, in the temperate zone and tropical countries, humidity has been reported to possibly play a more important role in viral spread than temperature, while in arid zones, cool, and dry conditions may facilitate the transmission of the virus [38]. In a study based on total interpretive structural modeling (TISM), community awareness, social distancing, age, air humidity and temperature, airflow and ventilation, and population density were identified as the main factors in the model. It was shown that the temperate countries of similar climatic zones and aged persons were more susceptible. Since many of these factors remain unchanged or out of human control, alteration in human behavior and the number of contacts are important factors in controlling the transmission [39].

\section{Epidemiology and Virus Pandemic Process}

At the end of 2019, a novel coronavirus was identified in Wuhan City, Hubei Province, China. Initially, the disease spread locally, affecting the people of Wuhan, and then spread around the world via international travelers. Consequently, it was announced as a worldwide pandemic by the WHO on 11 March 2020.

Following the first update from the WHO China Country Office in December 2019, the occurrence of COVID-19 has risen significantly. The SARS-CoV-2 spread to other areas of China because largely due to the Lunar New Year festival travel season. The first cases outside of China were identified in Thailand and Japan on 13 and 16 January 2020, respectively. By 25 January, the virus had been detected in other parts of the world, including Hong Kong, Macau, Australia, Malaysia, Singapore, France, and Japan. As of 3rd February, the number of countries afflicted with the virus was 24 and exceeded 213 by 13th April $[8,40]$.

COVID-19 incidence differs worldwide, and at the time of manuscript preparation (2 January 2021), over $84 \mathrm{M}$ confirmed cases, and $1.8 \mathrm{M}$ documented deaths were reported globally by the WHO from over 218 countries. The most common underlying risk factor was hypertension (12.8\%), followed by diabetes (5.3\%) and cardiovascular diseases (4.2\%). The incidence of COVID-19 among children of all ages has been reported, although is less frequent and less serious than the manifestations of adult [41]. Among all the cases reported to the WHO, the symptoms of the disease were reported critical, severe, and mild in $3 \%, 15 \%$, and $82 \%$ of cases, respectively. The overall mortality rate has been estimated at $2 \%$; nonetheless, different rates have been reported outside China. In research by Lee et al., the reproduction number (R0) for SARS-CoV-2 was 2.2, meaning that each infected person can transmit the virus to a mean of 2.2 persons [42]. In another study, the R0 of the virus was reported at 2.68 persons, and its epidemic doubling time was calculated at 6.4 days [43]. There are other reports with an estimated $\mathrm{R} 0$ of more than 3, while seasonal influenza in comparison has an estimated R0 of approximately 1.3 [44].

\section{COVID-19 Diagnosis}

Clinical diagnosis of COVID-19 can be divided into three different major approaches, including (1) epidemiological history, (2) clinical symptoms, and (3) laboratory examinations, such as nucleic acid detection or NGS, computed tomography (CT) imaging of the lung, and immunoassay-based tests, such as enzyme-linked immunosorbent assay (ELISA). Although the diagnosis was considered clinically diagnosed by case history and symptoms, the result necessitates a laboratory test for confirmation. Besides the advantages of laboratory tests, they limited by some criteria, including limited access due to cost of the test, time delayed from sample storage until to laboratory result preparations, lack of a common SOP (standard operating procedure) between various labs, as well as different viral loads on different anatomical sites of the body, and high mutation rates in the virus genome. Therefore, a proper diagnosis is related to a combination approach described [45]. The strategies used for diagnosing COVID-19 are summarized below, in general.

\section{Clinical Symptoms}

The most frequent clinical manifestations of COVID-19 generally include dry cough, pharyngitis, nausea, fever, 
dyspnea, chest tightness, anorexia, diarrhea, abdominal pain $[1,46]$. The clinical pictorial signs can be classified into three categories, as follows:

Mild disease: about $81 \%$ of cases feel unwell with the upper respiratory tract and mild/or non-pneumonia, mild fever, sore throat, nasal congestion, malaise, and headache.

Severe disease: these patients experience respiratory symptoms, such as dyspnea, tachypnea with respiratory rate $\geq 30 / \mathrm{min}$, blood oxygen saturation $\left(\mathrm{Sp}_{\mathrm{O}_{2}}\right) \leq 93 \%$, and lung infiltrates $>50 \%$ within 24 to $48 \mathrm{~h}$.

Critical disease: patients who suffer from acute respiratory distress syndrome (ARDS) may be followed by septic shock and multiple organ dysfunction, coagulation disorders, and even death [46].

\section{PCR-Based Methods}

Sine COVID-19 has emerged as a global health emergency, real-time RT-PCR assay has been reported as a sensitive and specific method to determine the presence of SARS-CoV-2 mainly in respiratory specimens. Three types of nucleic acid amplification tests (NAATs) have been developed, including real-time RT-PCR (rRT-PCR), reverse transcription loopmediated isothermal amplification (RT-LAMP), and reverse transcription polymerase chain reaction (RT-PCR) [47]. Two one-step quantitative RT-PCR (qRT-PCR) assays have further been developed to assess the presence of ORF1b and $\mathrm{N}$ regions of the SARS-CoV-2 genome to improve the diagnosis specificity as well as efficiency [10]. Studies have recently demonstrated that the detection limits of the twostep RT-PCR technique to find ORF1 and N pieces of the virus are less than ten copies per reaction [48]. Lei Ma et al. (2020) compared the data obtained from RT-qPCR based on (SYBR Green (SG) together with a probe which was designed for $\mathrm{M}$ gene sequence in the viral genome, and the findings revealed that the detection limit for such methods was ten copies per microliter of the sample. The efficiency of the SG method and probe-based RT-PCR was 73.81\% and $53.57 \%$, respectively [49]. Moreover, the sensitivity of the RT-PCR technique for nasopharyngeal secretions, throat discharge, urinary tract secretions, and a fecal sample was reported to be $60-68 \%, 65-72 \%, 50-54 \%$, and $57-63 \%$, respectively. Likewise, the specificity of the test was $100 \%$ [50]. For swab-based SARS-CoV-2 testing, nasopharyngeal and oropharyngeal specimens, as well as blood samples, are preferred [33]. Theoretically, saliva detection systems could also be used to detect the virus. Some virus strains have been detected in saliva as long as 29 days after infection. One of the greatest challenges against the PCR-based method is associated with the possible genetic variation of RNA viruses, which potentially reduces the efficiency or leads to false-negative outcomes [51].

\section{Detection of Viral Antigens}

Investigating antigens through immunoassay is another way of direct detection of the virus. The detection sensitivity of this method is of particular concern and most antigen tests have 50-90\% sensitivity. However, various advantages, including being rapid and not requiring expensive equipment, chemicals, and trained specialists, have made it a suitable point-of-care test (POCT) candidate [52]. Recently, a rapid SARS-CoV-2 antigen-based home test has been authorized by U.S. FDA [53], making antigen tests as a hopeful mean in controlling the pandemic. The WHO interim guidance, published on 11 September 2020, has recommended that SARS-CoV-2 antigen detection methods with $\geq 80 \%$ sensitivity and $\geq 97 \%$ specificity compared to a NAAT reference assay could be used where nucleic acidbased tests are not available or rapid test result is clinically necessary and also for contact tracing [54].

\section{Chest Radiographs in Patients with COVID-19}

The sensitivity of chest CT in the diagnosis of the SARS$\mathrm{CoV}-2$ has been reported as $97 \%$. Whereas RT-qPCR is a specific test for detecting SARS-CoV-2, this approach should be considered as an auxiliary diagnostic strategy due to its false-negative rate and lower sensitivity relative to CT. For patients with a negative RT-qPCR screening, repeated RT-qPCR tests parallel to chest CT scans have been recommended. Also, high-resolution CT (HRCT) could be beneficial for the early detection and determination of patient disease severity [55]. The most common HRCT findings include the bilateral pulmonary parenchymal ground-glass, consolidative pulmonary opacities, and sometimes with a rounded morphology of lung and a peripheral lung distribution. In many severe cases, the disease causes radiographic changes known as "white livers." In research carried out on 308 patients, $48 \%$ of the cases with negative RT-PCR results were diagnosed with COVID-19, by CT-scan findings [56]. Chest CT scan results during the hospitalization are time dependent [56]. GGO in lower lung lobes has been reported as the key finding up to 4 days after the first signs [57]. Through disease development, 5-8 days after the onset of early symptoms, the major features of CT detection are ground-glass, consolidation, and crazy paving. Such features increased towards days 9-13; thereafter, dense consolidation became a prevalent finding from the 14th day on [57].

\section{Serological Methods}

Serological tests, such as ELISA, IIFT, and neutralization, have been developed based on acute antibody responses to the virus. However, they are not applicable for diagnosis in acute cases within the first week of the disease but play a 
crucial role in epidemiological concerns, including determination of the asymptomatic patient, suspected individuals with negative RT-PCR results, immunity of recovered cases, as well as the overall attack rate [27]. IgG-IgM-based ELISA tests, which are used to evaluate the presence together with the number of antibodies against nucleocapsid $(\mathrm{N})$, and spike (S) proteins, have the highest accuracy among serological procedures developed [58]. SARS-CoV-2 ELISA kit sensitivity is still under investigation. The main challenge faced by Serological Methods is the cross-reaction of antibodies to similar epitopes. Further, since antibodies are produced during days to weeks post-infection, diagnostic assays based on antibodies are not suitable for early or active COVID-19 diagnosis [59].

\section{Diagnosis Based on Flow Cytometry Test of White Blood Cell (WBC) Count}

Analysis by flow cytometry is not a routine test for COVID19 detection, but recent studies have demonstrated that peripheral blood lymphocytes in ICU patients compared to non-ICU patients and normal individuals are lower, indicating lymphopenia. Even in patients with severe COVID-19, certain parameters, such as $\mathrm{CD}_{4} 5^{+}, \mathrm{CD}^{+}, \mathrm{CD}^{+}, \mathrm{CD} 8^{+}$, $\mathrm{CD} 19^{+}$, and $\mathrm{CD} 16 / 56^{+}$, counts are significantly lower. The CD4/CD8 ratio between patients and normal individuals has not been inverted [60].

\section{Diagnosis Based on Biochemical Findings}

In the early stage of the disease, a normal or decreased lymphocyte count has been reported. Furthermore, increased serum levels of AST and ALT enzymes and keratin have been reported in patients, which could be indicative of kidney and liver dysfunction [61]. While CRP and ESR increase in most patients, normal procalcitonin levels are observed [61]. Furthermore, the D-dimer level has a progressive increase in the acute phase of the disease and especially is associated with developing pulmonary embolism [62]. Patients with increased levels of acute-phase protein are at a higher risk of bacterial infections [63].

\section{People at Risk}

Evidence shows that patients with underlying medical conditions, such as Asthma (moderate-to-severe), Cerebrovascular disease, Hypertension, Immune deficiencies, Immunocompromised state (weakened immune system), Chemotherapy or immune weakening medicines-received patients, Cystic fibrosis, HIV, Type 1 diabetes mellitus, Smoking, Thalassemia, Increased age, male gender, and obesity, are at elevated risk of COVID-19 severe illness [63].

\section{Pregnant Women and Children}

Pregnant women should be considered as a high-risk group due to increased risk for serious illness and adverse pregnancy outcomes. The incidence of premature delivery in pregnant women admitted with COVID-19 was reported to be $47 \%$ [63, 64]. Only limited research has described the impact of COVID-19 on pregnancy, raising the importance of tracking suspected pregnant women before and after delivery. Besides, extensive monitoring of confirmed mothers and newborns has been strongly recommended [55]. Newborns should be isolated from infected mothers for at least 2 weeks or until the mother is no longer known to be contagious. Direct breastfeeding during this period is also not recommended [63]. The evidence of infectious SARS-CoV-2 in genital fluids remains uncertain, but since the COVID-19 is isolated from the face, the importance of infection risk by vaginal delivery for infants is highlighted. Nonetheless, contrary to earlier findings on COVID-19 in children, the latest studies indicate that the risk of infection with COVID-19 in children is equivalent to adults, but symptoms are relatively mild. The reason for these findings may be disparity between children and adults due to their immune systems [64].

\section{Treatment}

There is currently no specific treatment against COVID-19, and most guidelines emphasize early detection, isolation, and early diagnosis and treatment. In this area, only supportive care is provided, which includes rest, proper nutrition, monitoring vital signs and oxygen saturation, preventing dehydration, maintaining water, electrolytes, acids, and bases balance in the body [65]. Patients with high fever should be closely monitored. If patients' body temperature exceeds $38.5{ }^{\circ} \mathrm{C}$ with obvious discomfort, physical cooling or antipyretic drug treatment should be implemented. On this point, common drugs, including oral ibuprofen $(5-10 \mathrm{mg} / \mathrm{kg}$ ) and acetaminophen $(10-15 \mathrm{mg} / \mathrm{kg})$, might be prescribed. In case of seizure, children should be kept calm, and sedatives should be administered [66]. Oxygen therapy (e.g., nasal catheter and oxygen mask) must be used immediately following the emergence of hypoxia. If required, nasal high-flow oxygen therapy and mechanical ventilation must be performed [66].

Besides the above-mentioned supportive agents, sufficient amounts of vitamins in blood circulation should be considered. It has been shown that vitamin $\mathrm{C}$ decreases the expression of proinflammatory cytokines and hence can improve common cold and pneumonia symptoms. Moreover, it has been demonstrated that vitamin $\mathrm{D}$ reduces the risk of viral infection and mortality by decreasing the incidence of 
cytokine storms and regulating adaptive immunity. Vitamins $\mathrm{A}$ and $\mathrm{E}$ also regulate the innate and adaptive immune system as well as modulating cytokine production [67].

There is an urgent need for effective treatment against COVID-19 due to the high mortality rate of the disease especially in the elderly. In this respect, a wide range of different drugs, components, and devices are under investigation and in clinical development for treatment and control of this infection includes antibodies, antivirals, RNA-based therapeutics, and anti-inflammatory drugs [46]. Some other therapies, like plasma therapy, are also approved by the U.S. Food and Drug Administration, FDA [65]. In this part, we introduce some therapeutic agents for COVID-19 based on their technology or mechanism of action.

\section{Antiviral Drugs}

Although there is no specific antiviral treatment for COVID-19, several antiviral drugs, such as Lopinavir/ Ritonavir and other protease inhibitors have been tested. Lopinavir and Ritonavir were introduced as the first protease inhibitor compounds for the treatment of SARS$\mathrm{CoV}$ and have been tried to apply to the treatment of adult patients with COVID-19 pneumonia [68]. New lab studies show that another protease inhibitor known as nelfinavir has antiviral activity against SARS-CoV-2. However, favorable results are still not observed in animal studies [69]. Researchers in China showed that darunavir, the second generation of HIV protease inhibitor, can inhibit viral replication at the dose of $300 \mu \mathrm{M}$ [70]. Additionally, reports showed that glycyrrhizin suppresses virus absorption and penetration in the early stages of propagation. This compound has a lower toxicity rate, compared to other protease inhibitors (e.g., Ribavirin) [70]. Noteworthy, according to the latest updates of Coronavirus Drug and Treatment Tracker [71], Lopinavir/Ritonavir is not a promising candidate, and WHO has discontinued its clinical trial. Favipiravir is a drug that inhibits the RNAdependent RNA polymerase of influenza. This drug undergoes an intracellular phosphoribosylation to be in an active form known as favipiravir-RTP (favipiravir ribofuranosyl5 '-triphosphate), which is recognized as a substrate by RdRp and inhibits the RNA polymerase activity [72], and might have potential antiviral activity against SARSCoV-2. The preliminary results of a clinical trial on the effectiveness of favipiravir on COVID-19 treatment on 14 February 2020, showed it had a stronger antiviral activity, compared to Lopinavir/Ritonavir. Also, no significant side effect was observed in the favipiravir treatment group [73]. Arbidol is an anti-Influenza drug and membrane fusion inhibitor that has been prescribed for adults with COVID19 infection. A study showed that a $10-30 \mu \mathrm{M}$ concentration of Arbidol could effectively inhibit SARS-CoV-2 in vitro [74]. Nevertheless, its efficiency and safety remain to be confirmed. Oseltamivir, an anti-influenza neuraminidase inhibitor is currently being studied in clinical trials in combination with other drugs for the treatment of COVID-19 [75]. Metformin was originally introduced as an anti-influenza medication, and glucose lowering was one of its side effects. This drug phosphorylates the ACE2 receptor and changes its conformation that may lead to the reduction of the virus entry. Accordingly, a retrospective analysis by Pan Luo and colleagues demonstrated that metformin treatment decreased the mortality rates in diabetic COVID-19 patients [76].

Chloroquine is an anti-malarial drug and has been used for more than 70 years. This drug has broad-spectrum antiviral activities against various viruses, including HIV-I, Hepatitis-B, and HCoV-229E. In the case of SARS and MERS coronaviruses, it was shown that chloroquine could reduce viral replication [77]. It is assumed that chloroquine works by interfering with the glycosylation of ACE2 and increasing endosomal $\mathrm{pH}$. This drug can regulate the immune system and suppresses the production and release of inflammatory factors, such as tumor necrosis factor and interleukin 6 (IL-6), which mediates the inflammatory effects of viral diseases [78]. Moreover, it has been demonstrated that the combination of hydroxychloroquine (a less toxic analog of chloroquine) and azithromycin could clear the SARS-CoV-2 nasopharyngeal carriage in COVID-19 patients [79]. Despite all the above information, this drug is now classified as an unpromising therapy and has been discontinued for a clinical trial by WHO and FDA regarding its serious side effects to the heart and other organs [71].

Niclosamide, ivermectin, and Remdesivir are other drugs, with proposed activity as a COVID-19 treatment. Niclosamide and ivermectin are known as anthelmintic drugs, and their inhibitory activity against virus propagation has been shown by several studies [80,81]. Niclosamide treatment completely prevented the synthesis of viral antigens in vitro, which was found by immunofluorescence and immunoblot techniques. This drug is probably not involved in the primary stages of binding and entry into the cell and does not act as a protease inhibitor. However, understanding the action mechanism of Niclosamide requires further research [78]. Ivermectin seems to inhibit IMP $\alpha / \beta 1$-mediated nuclear import of viral proteins as the probable cause of its antiviral activity. It can inhibit the virus up to 5000 -fold at $48 \mathrm{~h}$ in vitro [80]. A nucleoside analog and a broad-spectrum antivirus, Remdesivir, is another potential drug for COVID-19 treatment. Animal-based experiments showed that Remdesivir reduces MERS-CoV viral lung loads in mice, improves lung capacity, and decreases lung tissue damages [81]. While Remdesivir has been approved as the first treatment option for COVID-19 by FDA for adult and pediatric 
patients 12 years of age and older and weighing at least $40 \mathrm{~kg}$, WHO reported that Remdesivir has little or even no effect on 28-day mortality or the in-hospital course of COVID-19 among hospitalized patients [71, 82].

Additionally, nebulized unfractionated heparin (UFH), used routinely as an anti-coagulant, has been shown to have anti-inflammatory, anti-SARS-CoV-2, and mucolytic activities, and now is in phase IV of the clinical trial. However, inhaled UFH in patients with acute lung injury has resulted in reduced coagulation activation, microvascular thrombosis, pulmonary dead space, and clinical deterioration [82].

\section{Anti-inflammatory Drugs}

The other strategy to treat COVID-19 patients is using antiinflammatory drugs, such as Glucocorticoids and Methylprednisolone. Glucocorticoids should be used based on the severity of systematic response, degree of shortness of breath, presence or absence of ARDS, and the chest imaging results. While it seems that steroids and methylprednisolone prolong virus shedding in patients with MERS-CoV, the WHO recommends not using this drug for COVID-19 treatment unless, for patients with ARDS $[42,70]$. Moreover, since the cytokine storm is common in severe cases of COVID-19, using immunomodulatory agents, such as tocilizumab (IL-6 inhibitor) and anakinra (IL-1 receptor antagonist) can be useful [83].

\section{Interferon-Based COVID-19 Treatment}

Interferons are not recommended for the treatment of patients with severe COVID-19, except in the clinical trial, and may only reduce viral load in the primary stage of the disease, which could help reduce the symptoms and the duration of the disease. So far, several clinical trials have been registered for different formulations of interferons type I ( $\alpha-2 b, \beta-1 a, \beta-1 b)$ and type III $(\lambda)$ [84]. In one study, administration of a nebulized interferon $\alpha-2 b$ resulted in more rapid viral clearance from the upper respiratory tract and reduction in systemic inflammation [85]. In another study, for severe COVID-19, interferon $\beta$-1a (in addition to hydroxychloroquine plus lopinavir-ritonavir or atazanavir-ritonavir) resulted in higher Day 14 discharge rate and lower Day 28 mortality rate compared to control group who did not receive interferon $\beta$-1a [86]. For mild to moderate COVID-19 cases, interferon $\beta-1 \mathrm{~b}$ in addition to lopinavir-ritonavir appeared to be effective in symptom alleviation and shortening days of viral shedding and length of hospital stay [87]. Also, prescription of peginterferonI- $\lambda 1$ for outpatients with COVID-19 accelerated viral clearance by Day 7 especially in those with high baseline viral load [88].

\section{Plasma and Antibody Therapy}

In late March 2020, the FDA approved the use of serum or plasma of recovered COVID-19 cases to treat COVID-19 patients [65]. Immunoglobulin can be used in severe cases, but its effectiveness requires further evaluation. Monoclonal Antibodies against the spike protein have been shown to reduce the severity of lung disease in human primates following MERS-CoV infection [89]. Other studies showed that regular intravenous immunoglobulin (IVIG) therapy could reduce hospitalization, promote recovery of patients, and reduce the use of ventilation. This kind of therapy is in clinical trial development (NCT04261426) [90]. As mentioned earlier, anti-inflammatory monoclonal antibodies, such as tocilizumab as an IL-6 receptor inhibitor [91] and ravulizumab, which prevents the activation of complement component 5 (NCT04369469), are also under investigation.

\section{Other Potential Therapies}

In addition to the above-mentioned methods, other possible treatment approaches might be considered, including aptamer oligonucleotides. Aptamers possess a particular 3D structure and can bind to their targets with high affinity. Coronaviruses and orthomyxoviridae (influenza viruses) both are RNA viruses with similar patterns of infection; hence, the aptamers developed against influenza viruses for detection and antiviral therapy can be considered as a potential therapeutic option against SARS-CoV-2 [92]. Furthermore, Chinese folk medicine which was effective in previous epidemics of coronavirus may be useful in managing the current outbreak. In this respect, myricetin, scutellarein, and baicalein were shown to be promising substances that could inhibit the hydrolysis of SARS-CoV [93]. On the other hand, based on the previous studies on SARS and MERS epidemics, the application of small interfering RNAs (siRNAs), a class of double-stranded and non-coding RNA molecules, was effective and might be useful for COVID-19 treatment as well [94].

\section{Vaccine Engineering Strategies}

Although vaccination is one of the most effective healthcare interventions, there are several social, clinical, and economic obstacles to vaccination, including a large number of people that might be reluctant to receive a new vaccine, the side effects of vaccination, the likelihood of varying vaccine effectiveness or poor efficacy in various populations, and access to the vaccine for certain people (including the logistics, cost, and quality of the vaccine) [95].

Several anti-SARS-CoV-2 vaccine candidates have been developed by various researchers, companies, and 
governments. Until the date of writing this manuscript (2 January 2021), 60 vaccine candidates have been registered in different phases of the clinical. Table 1 indicates the antiSARS-CoV-2 vaccine candidates who are in the third phase [96]. Many companies and institutes, such as Moderna, BioNTech/Pfizer, Novavax, and the University of Oxford/ AstraZeneca, together with governments and health organizations, are trying to accelerate the introduction of an effective vaccine against COVID-19 [96].

As shown in Table 1, a variety of vaccine developing platforms have been used to produce vaccine candidates against SARS-CoV-2. The technologies might be mainly divided into four different categories.

The first category is the whole virus vaccines (inactivated or live-attenuated virus), which is easy to prepare and is able to induce a rapid immune response in the human body against COVID-19. However, attenuated viral vaccines may cause disease in highly immunosuppressed patients [97].

The second category is the recombinant protein subunit vaccines, intended to sensitize the immune system to certain proteins of the virus. These types of vaccines are safe and induce humoral and cellular immune responses. However, they have some disadvantages, such as lower immunogenicity in comparison with inactive or live-attenuated virus vaccines, and need adjuvants and booster doses [98]. For SARS$\mathrm{CoV}-2$ protein subunit vaccines, the spike protein has been the main antigenic candidate. In addition to full-length spike protein that has been mostly used in its stabilized prefusion conformation [99], the receptor-binding domain (RBD), the $\mathrm{N}$-terminal domain (NTD), the S1 subunit, and the fusion proteins have been considered as the putative target antigens. Additionally, peptides and virus-like particles (VLPs) have been under investigation as subunit vaccine candidates [96].

The third category is the nucleic acid-based (DNA or RNA) vaccines, and the spike-coding gene has been their main immunogenic component. These kinds of vaccines are easy to design, but need an efficient delivery method [100]. Accordingly, RNA encapsulation with lipid nanoparticles (LNPs) and DNA electroporation have been widely used for the vaccines that are now in the advanced phases of clinical trial or have gained approval in some countries. DNA vaccines may bring about cell toxicity,

Table 1 Candidate SARS-CoV-2 vaccines at phase III clinical evaluation based on data up to 29 December 2020 (96)

\begin{tabular}{|c|c|c|c|c|}
\hline Platform & Vaccine name & Developer/manufacturer & Clinical trial number & Country of origin \\
\hline \multirow[t]{3}{*}{ RNA } & mRNA-1273 & Moderna & NCT04470427 & USA \\
\hline & BNT162 & BioNTech/Pfizer & NCT04368728 & Germany \\
\hline & $\mathrm{CVnCoV}$ & CureVac AG & NCT04674189 & Germany \\
\hline DNA & INO-4800 & Inovio Pharmaceuticals & NCT04642638 & USA \\
\hline \multirow[t]{3}{*}{ Protein subunit } & NVX-Cov 2373 & Novavax & 2020-004123-16 & USA \\
\hline & & & NCT04611802 & \\
\hline & Unnamed & Anhui Zhifei Longcom Biopharmaceutical & ChiCTR2000040153 & China \\
\hline \multirow[t]{11}{*}{ Non-replicating viral vector } & Gam-COVID-Vac & Gamaleya Research Institute & NCT04530396 & Russia \\
\hline & & & NCT04564716 & \\
\hline & & & NCT04642339 & \\
\hline & ChAdOx1-S & University of Oxford/AstraZeneca & ISRCTN89951424 & UK \\
\hline & & & NCT04516746 & \\
\hline & & & NCT04540393 & \\
\hline & & & CTRI/2020/08/027170 & \\
\hline & Ad5-nCOV & CanSino Biologics & NCT04526990 & China \\
\hline & & & NCT04540419 & \\
\hline & Ad26.COV2.S & Janssen Pharmaceutical & NCT04505722 & USA \\
\hline & & & NCT04614948 & \\
\hline \multirow[t]{8}{*}{ Inactivated } & BBIBP-CorV & Sinopharm & ChiCTR2000034780 & China \\
\hline & & & ChiCTR2000039000 & \\
\hline & & & NCT04612972 & \\
\hline & Coronavac & Sinovac & NCT04456595 & China \\
\hline & & & 669/UN6.KEP/EC/2020 & \\
\hline & & & NCT04582344 & \\
\hline & & & NCT04617483 & \\
\hline & BBV152 & Bharat Biotech & CTRI/2020/11/028976 & India \\
\hline Virus-like particles & CoVLP & Medicago & NCT04636697 & Canada, USA \\
\hline
\end{tabular}


and mRNA vaccines are unstable, and experimental nucleic acid-based vaccines should be extensively tested for safety and efficacy before being administered in the population [101].

Viral vector vaccine candidates as the fourth category of vaccine platforms are based on viral vectors with high safety profile, such as adenoviruses and measles virus that have been genetically modified to harbor and transfer antigen-coding genes. There are two different types of viral vectors: (1) replicating viral vectors that infect cells and encode vaccine antigens, as well as replicating and infecting other cells that will then generate more vaccine antigen, and (2) non-replicating viral vectors that initially enter the cells and encode the antigenic proteins, however no new virus particles are formed. As viral vector vaccines lead to the development of endogenous antigens, both humoral and cellular immune responses are induced. One potential advantage of this type of vaccine might be adequacy of a single-dose vaccination [102]. The main target antigen to be included in anti-SARS-CoV-2 viral vector vaccine candidates has been the spike protein, and nucleocapsid antigen has also been used in a limited number of clinical trials [96].

By the time of writing this article (2 January 2021), 60 and 172 vaccine candidates have been in clinical and preclinical evaluation, respectively [96]. The U.S. FDA has currently issued the emergency use authorization (EUA) of the two LNP-encapsulated mRNA-based vaccines, including BNT162b2 by Pfizer/BioNTech and mRNA-1273 by Moderna which were reported to have more than $95 \%$ and $94 \%$ efficacy, respectively. Russia approved its non-replicating adenovirus-based vaccine (Sputnik V) as the first country licensing a COVID-19 vaccine, and claiming its $91 \%$ efficacy [103]. In addition, non-replicating human adenovirus-based vaccine developed by CanSino Biologics has been authorized for use in the Chinese military, and the chimpanzee adenovirus-based ChAdOx1-S by the Oxford-AstraZeneca has been approved for use in the UK with more than $73 \%$ reported efficacy [104]. China and some Arab nations have approved the inactivated form of vaccine produced by the Chinese company Sinopharm which has been claimed to be $86 \%$ effective [105].

Although various vaccines are being authorized by the institutions and countries, there are critical considerations, including the longevity of the protective immune response, immunogenicity in children and old people, long-term safety, and immune-evading mutations of the virus in addition to the cost and logistics. As an example, Pfizer/BioNTech mRNA vaccine requires to be maintained and distributed at $-70{ }^{\circ} \mathrm{C}$ and should be administered in two doses that make its availability a challenge for many countries [106].

\section{Conclusion}

The SARS-CoV-2 outbreak was first detected in the City of Wuhan, China, on 12 December 2019. With 19,052,280 confirmed cases and 712,494 mortalities from over 213 countries (until 8 August 2020), the spread of the coronavirus has been transformed into a global pandemic. The virus is spreading rapidly among people and within countries. There is a great deal of misleading information and knowledge gaps in this recently emerging pathogen. Currently, there are no effective antiviral drugs and vaccine in controlling COVID-19, and transmission mitigation measures to drive the effective value of R0, below 1 , are the best available options to reduce the epidemic. Personal measures, such as mask-wearing and hand hygiene, physical and social distancing measures, such as stopping mass gatherings, avoiding crowded spaces, as well as movement measures to limit movement of persons locally or nationally, are among the mitigation activities to be applied [106]. Recently, face covering in public has been reported to be the most effective means to prevent interhuman transmission, while other mitigation measures, such as social distancing, are found to be insufficient by themselves in protecting the public [107].

Accordingly, we reviewed the latest updates on multiple aspects of SARS-CoV-2, including structure, origin, pathogenesis, epidemiology, diagnostic, and treatment strategies. Based on the evidence currently available as well as important unknowns and uncertainties about COVID-19, such as case fatality rate (CFR), whether infectiousness starts before onset of symptoms, presence of a large number of asymptomatic cases, and duration of the infectious period, the effective SARS-CoV-2 control necessitates tremendous coordination among governments, scientists, as well as global health authorities.

Author Contributions All the authors conceived this study. ABP, MB, $\mathrm{HB}$, and SF performed the literature search and prepared the manuscript. SHA created the figures and participated in drafting the document. AA and SHA reviewed the manuscript and checked for language errors. Additionally, all the authors critically revised the paper. MSV, $\mathrm{AA}$, and KA were mentors and contributed to the supervision of the entire work. All the authors read and approved the final manuscript.

Funding None. No funding acknowledgments to declare.

\section{Compliance with Ethical Standards}

Conflict of interest The authors declare no conflict of interest. 


\section{References}

1. del Rio C, Malani PN (2020) 2019 Novel coronavirus-important information for clinicians. JAMA 323(11):1039-1040

2. Gorbalenya AE (2020) Severe acute respiratory syndromerelated coronavirus - the species and its viruses, a statement of the Coronavirus Study Group. BioRxiv. https://doi. org/10.1101/2020.02.07.937862

3. Corman VM, Muth D, Niemeyer D, Drosten C (2018) Hosts and sources of endemic human coronaviruses. Adv Virus Res 100:163-188

4. Sexton NR, Smith EC, Blanc H, Vignuzzi M, Peersen OB, Denison MR (2016) Homology-based identification of a mutation in the coronavirus RNA-dependent RNA polymerase that confers resistance to multiple mutagens. J Virol 90(16):7415-7428

5. Chen Y, Liu Q, Guo D (2020) Emerging coronaviruses: genome structure, replication, and pathogenesis. J Med Virol 92(4):418-423

6. Zhou G, Zhao Q (2020) Perspectives on therapeutic neutralizing antibodies against the Novel Coronavirus SARS-CoV-2. Int J Biol Sci 16(10): 1718

7. World Health Organization (2020) Transmission of SARSCoV-2: implications for infection prevention precautions: scientific brief, 09 July 2020. World Health Organization, Geneva

8. Wu P, Hao X, Lau EHY, Wong JY, Leung KSM, Wu JT et al (2020) Real-time tentative assessment of the epidemiological characteristics of novel coronavirus infections in Wuhan, China, as at 22 January 2020. Euro Surveill Eur Commun Dis Bull 25(3):2000044

9. Ganier C, Du-Harpur X, Harun N, Wan B, Arthurs C, Luscombe $\mathrm{NM}$ et al (2020) CD147 (BSG) but not ACE2 expression is detectable in vascular endothelial cells within single cell RNA sequencing datasets derived from multiple tissues in healthy individuals. bioRxiv. https://doi.org/10.1101/2020.05.29.123513

10. Chang D, Lin M, Wei L, Xie L, Zhu G, Cruz CSD et al (2020) Epidemiologic and clinical characteristics of novel coronavirus infections involving 13 patients outside Wuhan, China. JAMA 323(11):1092-1093

11. Benvenuto D, Giovanetti M, Ciccozzi A, Spoto S, Angeletti S, Ciccozzi M (2020) The 2019-new coronavirus epidemic: evidence for virus evolution. J Med Virol 92(4):455-459

12. Xu X, Chen P, Wang J, Feng J, Zhou H, Li X et al (2020) Evolution of the novel coronavirus from the ongoing Wuhan outbreak and modeling of its spike protein for risk of human transmission. Sci China Life Sci 63(3):457-460

13. Li C, Yang Y, Ren L (2020) Genetic evolution analysis of 2019 novel coronavirus and coronavirus from other species. Infect Genet Evol 82:104285

14. Coleman CM, Frieman MB (2014) Coronaviruses: important emerging human pathogens. J Virol 88(10):5209-5212

15. Navas-Martín S, Weiss SR (2004) Coronavirus replication and pathogenesis: implications for the recent outbreak of severe acute respiratory syndrome (SARS), and the challenge for vaccine development. J Neurovirol 10(2):75-85

16. Lai MMC, Cavanagh D (1997) The molecular biology of coronaviruses. In: Maramorosch K, Murphy FA, Shatkin AJ (eds) Advances in virus research, vol 48. Academic, Cambridge, pp $1-100$

17. Naqvi AAT, Fatima K, Mohammad T, Fatima U, Singh IK, Singh A et al (2020) Insights into SARS-CoV-2 genome, structure, evolution, pathogenesis and therapies: structural genomics approach. Biochim Biophys Acta Mol Basis Dis 1866(10):165878

18. Chu H, Chan JF-W, Wang Y, Yuen TT-T, Chai Y, Hou Y et al (2020) Comparative replication and immune activation profiles of SARS-CoV-2 and SARS-CoV in human lungs: an ex vivo study with implications for the pathogenesis of COVID-19. Clin Infect Dis 71(6): 1400-1409

19. Hoffmann M, Kleine-Weber H, Krüger N, Mueller MA, Drosten C, Pöhlmann S (2020) The novel coronavirus 2019 (2019-nCoV) uses the SARS-coronavirus receptor ACE2 and the cellular protease TMPRSS2 for entry into target cells. BioRxiv. https://doi. org/10.1101/2020.01.31.929042

20. Damas J, Hughes GM, Keough KC, Painter CA, Persky NS, Corbo M et al (2020) Broad host range of SARS-CoV-2 predicted by comparative and structural analysis of ACE2 in vertebrates. Proc Natl Acad Sci USA 117(36):22311-22322

21. Chen Y, Guo Y, Pan Y, Zhao ZJ (2020) Structure analysis of the receptor binding of 2019-nCoV. Biochem Biophys Res Commun 525(1):135-140

22. Zheng M, Song L (2020) Novel antibody epitopes dominate the antigenicity of spike glycoprotein in SARS-CoV-2 compared to SARS-CoV. Cell Mol Immunol 17:1-3

23. Hogue BG, Machamer CE (2008) Coronavirus structural proteins and virus assembly. Nidoviruses. American Society of Microbiology, Washington, DC, pp 179-200

24. Yap JK, Moriyama M, Iwasaki A (2020) Inflammasomes and pyroptosis as therapeutic targets for COVID-19. J Immunol. https ://doi.org/10.4049/jimmunol.2000513

25. Yang M (2020) Cell pyroptosis, a potential pathogenic mechanism of 2019-nCoV infection. Available at SSRN https://ssrn. com/abstract $=3527420$

26. Azkur AK, Akdis M, Azkur D, Sokolowska M, van de Veen $\mathrm{W}$, Brüggen $\mathrm{MC}$ et al (2020) Immune response to SARS-CoV-2 and mechanisms of immunopathological changes in COVID-19. Allergy 75(7):1564-1581

27. Long Q-X, Liu B-Z, Deng H-J, Wu G-C, Deng K, Chen Y-K et al (2020) Antibody responses to SARS-CoV-2 in patients with COVID-19. Nat Med 26:1-4

28. Cañete PF, Vinuesa CG (2020) COVID-19 makes B cells forget, but $\mathrm{T}$ cells remember. Cell 183(1):13-15

29. Melenotte C, Silvin A, Goubet A-G, Lahmar I, Dubuisson A, Zumla A et al (2020) Immune responses during COVID-19 infection. OncoImmunology 9(1):1807836

30. Chen Z, Wherry EJ (2020) T cell responses in patients with COVID-19. Nat Rev Immunol 20:1-8

31. Prompetchara E, Ketloy C, Palaga T (2020) Immune responses in COVID-19 and potential vaccines: lessons learned from SARS and MERS epidemic. Asian-Pac J Allergy Immunol 38(1):1-9

32. Shi Y, Wang Y, Shao C, Huang J, Gan J, Huang X et al (2020) COVID-19 infection: the perspectives on immune responses. Cell Death Differ 27:1451-1454

33. Zhu N, Zhang D, Wang W, Li X, Yang B, Song J et al (2020) A novel coronavirus from patients with pneumonia in China, 2019. N Engl J Med 382(8):727-733

34. Meckiff BJ, Ramírez-Suástegui C, Fajardo V, Chee SJ, Kusnadi A, Simon H, et al (2020) Single-cell transcriptomic analysis of SARS-CoV-2 reactive CD4 ${ }^{+}$T cells. Available at SSRN https:// doi.org/10.2139/ssrn.3641939

35. Feng B, Xu K, Gu S, Zheng S, Zou Q, Xu Y et al (2020) Multiroute transmission potential of SARS-CoV-2 in healthcare facilities. J Hazard Mater 402:123771

36. Chan JF-W, Yuan S, Kok K-H, To KK-W, Chu H, Yang J et al (2020) A familial cluster of pneumonia associated with the 2019 novel coronavirus indicating person-to-person transmission: a study of a family cluster. Lancet 395(10223):514-523

37. Kampf G, Todt D, Pfaender S, Steinmann E (2020) Persistence of coronaviruses on inanimate surfaces and their inactivation with biocidal agents. J Hosp Infect 104(3):246-251

38. Yuan S, Jiang S, Li Z-L (2020) Do humidity and temperature impact the spread of the novel coronavirus? Front Public Health $8: 240$ 
39. Lakshmi Priyadarsini S, Suresh M (2020) Factors influencing the epidemiological characteristics of pandemic COVID 19: a TISM approach. Int J Healthc Manag 13(2):89-98

40. Araban M, Karimy M, Mesri M, Armoon B, Koohestani HR, Azani H (2020) Epidemiological, clinical characteristics of coronavirus-infected disease (COVID-19) among sample of Iranian community: funding from survey in central of Iran. https://doi. org/10.21203/rs.3.rs-32797/v1

41. Dong Y, Mo X, Hu Y, Qi X, Jiang F, Jiang Z et al (2020) Epidemiology of COVID-19 among children in China. Pediatrics 145(6):e20200702

42. Vetter P, Eckerle I, Kaiser L (2020) COVID-19: a puzzle with many missing pieces. Br Med J 368:m627

43. Han W, Quan B, Guo Y, Zhang J, Lu Y, Feng G et al (2020) The course of clinical diagnosis and treatment of a case infected with coronavirus disease 2019. J Med Virol 92(5):461-463

44. D'Arienzo M, Coniglio A (2020) Assessment of the SARS$\mathrm{CoV}-2$ basic reproduction number, $\mathrm{R} 0$, based on the early phase of COVID-19 outbreak in Italy. Biosaf Health 2(2):57-59

45. Wang Y, Kang H, Liu X, Tong Z (2020) Combination of RTqPCR testing and clinical features for diagnosis of COVID-19 facilitates management of SARS-CoV-2 outbreak. J Med Virol 92(6):538-539

46. Cascella M, Rajnik M, Cuomo A, Dulebohn SC, Di Napoli R (2020) Features, evaluation and treatment coronavirus (COVID19). In: Statpearls [internet]. StatPearls Publishing, Treasure Island

47. Zhai P, Ding Y, Wu X, Long J, Zhong Y, Li Y (2020) The epidemiology, diagnosis and treatment of COVID-19. Int J Antimicrob Agents 55(5): 105955

48. Ryu S, Chun BC, Korean Society of Epidemiology 2019-nCoV Task Force Team. An interim review of the epidemiological characteristics of (2019) novel coronavirus. Epidemiol Health 2020(42):e2020006

49. Ma L, Zeng F, Cong F, Huang B, Huang R, Ma J et al (2019) Development of a SYBR green-based real-time RT-PCR assay for rapid detection of the emerging swine acute diarrhea syndrome coronavirus. J Virol Methods 265:66-70

50. Yam W, Chan K, Poon L, Guan Y, Yuen K, Seto W et al (2003) Evaluation of reverse transcription-PCR assays for rapid diagnosis of severe acute respiratory syndrome associated with a novel coronavirus. J Clin Microbiol 41(10):4521-4524

51. Han P, Ivanovski S (2020) Saliva - friend and foe in the COVID19 outbreak. Diagnostics 10(5):290

52. Dinnes J, Deeks JJ, Adriano A, Berhane S, Davenport C, Dittrich $S$ et al (2020) Rapid, point-of-care antigen and molecular-based tests for diagnosis of SARS-CoV-2 infection. Cochrane Database Syst Rev 8:CD013705

53. Food and Drug Administration (2020) Coronavirus (COVID-19) update: FDA authorizes antigen test as first over-the-counter fully at-home diagnostic test for COVID-19. FDA News Release. https ://www.fda.gov/news-events/press-announcements/coronaviru s-covid-19-update-fda-authorizes-antigen-test-first-over-count er-fully-home-diagnostic. Accessed 26 Feb 2021

54. World Health Organization (2020) Antigen-detection in the diagnosis of SARS-CoV-2 infection using rapid immunoassays: interim guidance, 11 September 2020. World Health Organization, Geneva

55. Panahi L, Amiri M, Pouy S (2020) Risks of novel coronavirus disease (COVID-19) in pregnancy; a narrative review. Arch Acad Emerg Med 8(1):e34

56. Fang Y, Zhang H, Xie J, Lin M, Ying L, Pang P et al (2020) Sensitivity of chest CT for COVID-19: comparison to RT-PCR. Radiology. https://doi.org/10.1148/radiol.2020200432

57. Pan F, Ye T, Sun P, Gui S, Liang B, Li L et al (2019) Time course of lung changes on chest CT during recovery from novel coronavirus (COVID-19) pneumonia. Radiology. https://doi. org/10.1148/radiol.2020200370

58. Vengesai A, Midzi H, Kasambala M, Mutandadzi H, Mduluza-Jok T, Rusakaniko S et al (2020) A systematic and metaanalysis review on the diagnostic accuracy of antibodies in the serological diagnosis of COVID-19. https://doi.org/10.21203/ rs.3.rs-34638/v2

59. Bastos ML, Tavaziva G, Abidi SK, Campbell JR, Haraoui L-P, Johnston JC et al (2020) Diagnostic accuracy of serological tests for COVID-19: systematic review and meta-analysis. BMJ 370:m2516

60. Fan BE, Chong VCL, Chan SSW, Lim GH, Lim KGE, Tan GB et al (2020) Hematologic parameters in patients with COVID19 infection. Am J Hematol 95(6):E131-E134

61. Wu Y, Li H, Guo X, Yoshida EM, Mendez-Sanchez N, Sandri GBL et al (2020) Incidence, risk factors, and prognosis of abnormal liver biochemical tests in COVID-19 patients: a systematic review and meta-analysis. Hepatol Int. https://doi. org/10.1007/s12072-020-10074-6

62. Garcia-Olivé I, Sintes H, Radua J, Capa JA, Rosell A (2020) D-dimer in patients infected with COVID-19 and suspected pulmonary embolism. Respir Med 169:106023

63. Jordan RE, Adab P, Cheng K (2020) COVID-19: risk factors for severe disease and death. Br Med J 368:m1198

64. Zimmermann P, Curtis N (2020) COVID-19 in children, pregnancy and neonates: a review of epidemiologic and clinical features. Pediatr Infect Dis J 39(6):469-477

65. Sediqi N, Sediqi M (2020) A review on pathophysiology and pharmacological treatment of COVID-19. Int Innov Res Sci Stud 3(2):110-122

66. Cao W (2020) Clinical features and laboratory inspection of novel coronavirus pneumonia (COVID-19) in Xiangyang, Hubei. medRxiv. https://doi.org/10.1101/2020.02.23.20026 963

67. Fiorino S, Gallo C, Zippi M, Sabbatani S, Manfredi R, Moretti $\mathrm{R}$ et al (2020) COVID-19 perfect storm (Part II): role of vitamins as therapy or preventive strategy in aged people

68. Shen K, Yang Y, Wang T, Zhao D, Jiang Y, Jin R et al (2020) Diagnosis, treatment, and prevention of 2019 novel coronavirus infection in children: experts' consensus statement. World J Pediatr 16(3):223-231

69. Ohashi H, Watashi K, Saso W, Shionoya K, Iwanami S, Hirokawa T et al (2020) Multidrug treatment with nelfinavir and cepharanthine against COVID-19. bioRxiv. https://doi. org/10.1101/2020.04.14.039925

70. Luo P, Liu D, Li J (2020) Pharmacologic perspective: glycyrrhizin may be an efficacious therapeutic agent for COVID- 19 . Int J Antimicrob Agents 55(6):105995

71. FasterCures MI (2020) COVID-19 treatment and vaccine tracker. Milken Institute. https://covid-19tracker.milkeninst itute.org. Accessed 26 Feb 2021

72. Agrawal U, Raju R, Udwadia ZF (2020) Favipiravir: A new and emerging antiviral option in COVID-19. Med J Armed Forces India 76(4):370-376

73. Kramer DG, Da Silva MJL, Da Silva GSE, De Moura AMMA, Junior GBC, De Sousa AM et al (2020) Favipiravir as a potential drug in the treatment of COVID-19. Int J Res GRANTHAALAYAH 8(4):7-12

74. Zhu Z, Lu Z, Xu T, Chen C, Yang G, Zha T et al (2020) Arbidol monotherapy is superior to lopinavir/ritonavir in treating COVID-19. J Infect 81(1):e21-e23

75. Valizadeh R, Dadashzadeh N, Zakeri R, Kellner SJ, Rahimi MM (2020) Drug therapy in hospitalized patients with very severe symptoms following COVID-19. Med Sci 35:e79

76. Luo P, Qiu L, Liu Y, Liu X-L, Zheng J-L, Xue H-Y et al (2020) Metformin treatment was associated with decreased mortality 
in COVID-19 patients with diabetes in a retrospective analysis. Am J Trop Med Hyg 103(1):69-72

77. Cortegiani A, Ingoglia G, Ippolito M, Giarratano A, Einav S (2020) A systematic review on the efficacy and safety of chloroquine for the treatment of COVID-19. J Crit Care 57:279-283

78. Amawi H, Abu Deiab GaI, Aljabali AA, Dua K, Tambuwala MM (2020) COVID-19 pandemic: an overview of epidemiology, pathogenesis, diagnostics and potential vaccines and therapeutics. Ther Deliv 11(4):245-268

79. Gautret P, Lagier J-C, Parola P, Meddeb L, Mailhe M, Doudier B et al (2020) Hydroxychloroquine and azithromycin as a treatment of COVID-19: results of an open-label non-randomized clinical trial. Int J Antimicrob Agents 56(1):105949

80. Caly L, Druce JD, Catton MG, Jans DA, Wagstaff KM (2020) The FDA-approved drug ivermectin inhibits the replication of SARS-CoV-2 in vitro. Antivir Res 178:104787

81. Wang M, Cao R, Zhang L, Yang X, Liu J, Xu M et al (2020) Remdesivir and chloroquine effectively inhibit the recently emerged novel coronavirus (2019-nCoV) in vitro. Cell Res 30(3):269-271

82. van Haren FM, Page C, Laffey JG, Artigas A, Camprubi-Rimblas M, Nunes Q et al (2020) Nebulised heparin as a treatment for COVID-19: scientific rationale and a call for randomised evidence. Crit Care 24(1):1-11

83. Zhang W, Zhao Y, Zhang F, Wang Q, Li T, Liu Z et al (2020) The use of anti-inflammatory drugs in the treatment of people with severe coronavirus disease 2019 (COVID-19): the experience of clinical immunologists from China. Clin Immunol 214:108393

84. National Library of Medivcine (US) (2020) Search result, 115 studies found for: interferon ICOVID-19. Clinicaltrial.gov. https:// www.clinicaltrials.gov/ct2/results?cond=COVID-19\&term=inter feron $\&$ cntry $=\&$ state $=\&$ city $=\&$ dist $=\&$ Search $=$ Search

85. Calabrese LH, Lenfant T, Calabrese C (2020) Interferon therapy for COVID-19 and emerging infections: prospects and concerns. Clevel Clinic J Med. https://doi.org/10.3949/ccjm.87a.ccc066

86. Davoudi-Monfared E, Rahmani H, Khalili H, Hajiabdolbaghi M, Salehi M, Abbasian L et al (2020) A randomized clinical trial of the efficacy and safety of interferon $\beta-1 \mathrm{a}$ in treatment of severe COVID-19. Antimicrob Agents Chemother. https://doi. org/10.1128/aac.01061-20

87. Hung IF-N, Lung K-C, Tso EY-K, Liu R, Chung TW-H, Chu $\mathrm{M}-\mathrm{Y}$ et al (2020) Triple combination of interferon beta-1b, lopinavir-ritonavir, and ribavirin in the treatment of patients admitted to hospital with COVID-19: an open-label, randomised, phase 2 trial. Lancet 395(10238):1695-1704

88. Feld JJ, Kandel C, Biondi MJ, Kozak RA, Zahoor MA, Lemieux $\mathrm{C}$ et al (2020) Peginterferon-lambda for the treatment of COVID19 in outpatients. medRxiv

89. Du L, Yang Y, Zhou Y, Lu L, Li F, Jiang S (2017) MERS-CoV spike protein: a key target for antivirals. Expert Opin Ther Targets 21(2):131-143

90. Xie Y, Cao S, Dong H, Li Q, Chen E, Zhang W et al (2020) Effect of regular intravenous immunoglobulin therapy on prognosis of severe pneumonia in patients with COVID-19. J Infect 81(2):318-356

91. Guaraldi G, Meschiari M, Cozzi-Lepri A, Milic J, Tonelli R, Menozzi M et al (2020) Tocilizumab in patients with severe
COVID-19: a retrospective cohort study. Lancet Rheumatol 2(8):e474-e484

92. Liebich S. Potent SELEX aptamer-based therapeutic method for novel SARS-CoV2 virus disease (COVID-19)

93. Nascimento Junior JAC, Santos AM, Quintans-Júnior LJ, Walker CIB, Borges LP, Serafini MR (2020) SARS, MERS and SARSCoV-2 (COVID-19) treatment: a patent review. Expert Opin Ther Pat 30(8):567-579

94. Ghosh S, Firdous SM, Nath A (2020) siRNA could be a potential therapy for COVID-19. EXCLI J 19:528

95. Corey L, Mascola JR, Fauci AS, Collins FS (2020) A strategic approach to COVID-19 vaccine R\&D. Science 368(6494):948-950

96. World Health Organization (2020). Draft landscape of COVID19 candidate vaccines. 29 December 2020. www.who.int/publi cations $/ \mathrm{m} /$ item/draft-landscape-of-covid-19-candidate-vaccines

97. Roper RL, Rehm KE (2009) SARS vaccines: where are we? Expert Rev Vaccines 8(7):887-898

98. Du L, He Y, Zhou Y, Liu S, Zheng B-J, Jiang S (2009) The spike protein of SARS-CoV—a target for vaccine and therapeutic development. Nat Rev Microbiol 7(3):226-236

99. Arashkia A, Jalilvand S, Mohajel N, Afchangi A, Azadmanesh K, Salehi-Vaziri M et al (2020) Severe acute respiratory syndrome-coronavirus-2 spike (S) protein based vaccine candidates: state of the art and future prospects. Rev Med Virol. https://doi. org/10.1002/rmv.2183

100. Liu MA (2019) A comparison of plasmid DNA and mRNA as vaccine technologies. Vaccines 7(2):37

101. Pang J, Wang MX, Ang IYH, Tan SHX, Lewis RF, Chen JI-P et al (2020) Potential rapid diagnostics, vaccine and therapeutics for 2019 novel Coronavirus (2019-nCoV): a systematic review. J Clin Med 9(3):623

102. van Riel D, de Wit E (2020) Next-generation vaccine platforms for COVID-19. Nat Mater 19(8):810-812

103. Mullard A (2020) COVID-19 vaccines buoy hope. Nat Reviews Drug Discov 20(1):8

104. Medicines and Healthcare Products Regulatory Agency (2020) Information for healthcare professionals on COVID-19 vaccine AstraZeneca. GOV.UK. https://www.gov.uk/government/publi cations/regulatory-approval-of-covid-19-vaccine-astrazeneca/ information-for-healthcare-professionals-on-covid-19-vaccineastrazeneca. Accessed 26 Feb 2021

105. Cyranoski D (2020) Arab nations first to approve Chinese COVID vaccine-despite lack of public data. Nature. https:// www.nature.com/articles/d41586-020-03563-z. Accessed 26 Feb 2021

106. Mahase E (2020) COVID-19: What do we know about the late stage vaccine candidates? Br Med J 371:m4576

107. Zhang R, Li Y, Zhang AL, Wang Y, Molina MJ (2020) Identifying airborne transmission as the dominant route for the spread of COVID-19. Proc Natl Acad Sci USA 117(26):14857-14863

Publisher's Note Springer Nature remains neutral with regard to jurisdictional claims in published maps and institutional affiliations. 